\title{
Search for the ideal oral rehydration solution: studies in a model of secretory diarrhoea
}

\author{
E J Elliott, A J M Watson, J A Walker-Smith, M J G Farthing
}

\begin{abstract}
In situ perfusion of whole rat small intestine was used to compare the efficacy of five oral rehydration solutions in promoting water and sodium absorption in normal intestine and secreting intestine after exposure to cholera toxin. Solutions varied in their sodium (35-90 $\mathrm{mmol} / \mathrm{l})$ and glucose (111-200 mmol/l) concentrations, molar ratio of glucose:sodium (1.25.8 ), and osmolality (281-331 mOsmol/kg), and contained either bicarbonate $(18-30 \mathrm{mmol} / \mathrm{l})$ or citrate $(10 \mathrm{mmol} / \mathrm{l})$. In normal intestine all solutions promoted net water absorption. Cholera toxin induced reproducible water secretion but all solutions reversed this to absorption. Water absorption was greatest with solutions containing sodium $60 \mathrm{mmol} / 1$ and glucose 111 or $140 \mathrm{mmol} / \mathrm{l}$, and with a glucose:sodium ratio $\sim 2$, in both normal and secreting intestine. All solutions promoted net glucose absorption in both normal and secreting intestine. Net sodium absorption occurred with solutions containing $\geqslant 60 \mathrm{mmol} / 1$ sodium in normal intestine but sodium secretion occurred from all solutions in secreting intestine. Sodium movement was directly related to the sodium concentration of the solution and sodium secretion occurred despite net water and glucose absorption. We consider that these studies may guide future development of oral rehydration solutions.
\end{abstract}

In view of its implications for treatment the discovery that glucose stimulates water and sodium absorption in the small intestine has been hailed as 'potentially the most important medical advance this century.' Glucose-sodium cotransport remains intact in cholera and other diarrhoeal diseases and justifies the use of oral glucose-electrolyte solutions for treatment of the dehydration associated with acute gastroenteritis. ${ }^{23}$ Controversy persists, however, regarding their 'ideal' composition, particularly with respect to their content of carbohydrate, ${ }^{+}$ sodium, ${ }^{56}$ and base. ${ }^{7-9}$ While the World Health Organisation recommends a single solution for use world wide, the development of many commercial solutions has left practitioners in developed communities in a state of confusion. Rather than search for a single universal oral rehydration solution, solutions should be tailored according to the aetiology of acute diarrhoea.

It has been proposed that an animal model may be useful for preliminary screening of new oral rehydration solutions before evaluation in a controlled clinical trial. ${ }^{10}$ Previous animal studies have usually involved perfusion of such solutions through short segments of normal rat intestine, ${ }^{10-13}$ but these findings may not be applicable to disease states in which intestinal transport processes may be disrupted. An animal model of secretory diarrhoea using cholera toxin has been developed ${ }^{14}$ and preliminary studies have shown by perfusion of the entire rat jejunum and ileum that there are differences in the efficacy of currently available and experimental oral rehydration solutions with respect to water and sodium absorption. ${ }^{15}$

The aims of the present study were (i) to further characterise this in situ steady-state perfusion model of secretory diarrhoea by determining the optimal conditions for induction of a secretory state, (ii) to evaluate the overall effect of the composition of oral rehydration solutions on water and electrolyte absorption, and (iii) to assess the contributions of some of the major constituents. We also investigated whether there were quantitative or qualitative differences in the efficacy of such solutions in normal and secreting rat intestine. Results suggest that water absorption is influenced by the osmolality of an oral rehydration solution, its glucose and electrolyte composition, and the ratio of glucose:sodium concentration.

\section{Methods}

IN SITU STEADY-STATE PERFUSION OF RAT SMALL INTESTINE

Perfusion of rat small intestine was performed as described previously. ${ }^{15}$ Briefly, male Wistar rats, 180-240 g, were fasted for 18 hours with free access to water, then anaesthetised with intraperitoneal sodium pentobarbitone $(60 \mathrm{mg} / \mathrm{kg})$, and maintained with $30 \mathrm{mg} / \mathrm{kg}$ by intramuscular injection as required. At laparotomy polyvinyl cannulas were inserted into the proximal jejunum, 2-3 cm distal to the ligament of Treitz, and into the terminal ileum, $2-3 \mathrm{~cm}$ from the ileocaecal junction. The proximal cannula was used to deliver the perfusate and the distal cannula to collect the effluent. Body temperature was maintained at $37 \pm 0.5^{\circ} \mathrm{C}$ by a heating pad and overhead lamp. Before perfusion residual small intestinal contents were removed by gentle lavage with $150 \mathrm{mmol} / \mathrm{l}$ sodium chloride, rendered isotonic to rat plasma with $25 \mathrm{mmol} / \mathrm{l}$ mannitol. The entire small intestine, excluding the duodenum to prevent contamination by pancreatic secretions, was perfused continuously with fluid at a temperature of $37^{\circ} \mathrm{C}$ using a Braun ED2 pump at a rate of $0.5 \mathrm{ml} / \mathrm{min}$. After an equilibration period of 60 minutes with the test solution (during which steady-state was achieved in all cases), three consecutive 10 minute collections were taken from the distal cannula and analysed for glucose, electrolyte, and poly- 
(A)

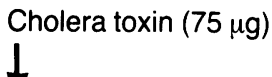

$\downarrow$

Time (hours)

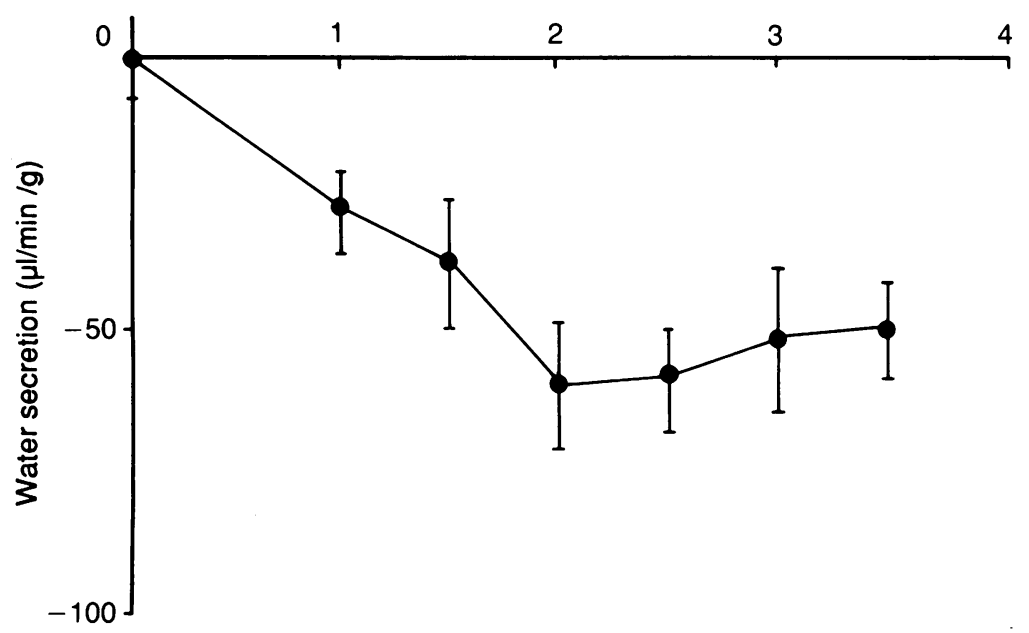

Figure 1: (A) Time course of secretory response: water secretion during isotonic 150 mmolll sodium chloride perfusion after exposure to 75 ug cholera toxin. Results are expressed as mean (SEM) $(n=6)$. Water secretion did not alter significantly between 2 and $3 \cdot 5$ hours. $(B)$ Optimal dose of cholera toxin: water secretion after 2 hours' exposure to cholera toxin in a dose of between 5 and $100 \mathrm{ug}$. Results are expressed as mean (SEM) $(n=6-12)$. Water absorption did not vary significantly with doses between 50 and $100 \mu \mathrm{g}$.
(B)

Dose of cholera toxin $(\mu \mathrm{g})$

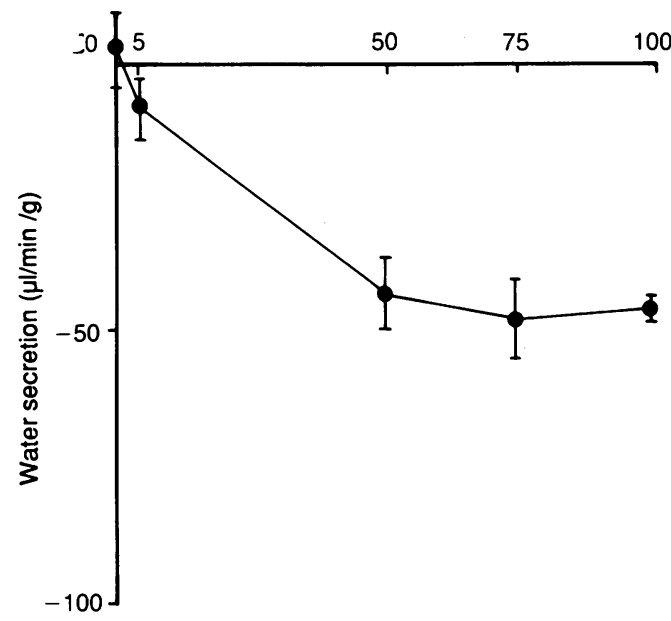

INDUCTION OF A SECRETORY STATE

A secretory state was induced before perfusion of some rats by the instillation of pure cholera toxin (Sigma Chemical, Poole, Dorset; Product No C-9025, Lot 14F-4054) in $5 \mathrm{ml} 150 \mathrm{mmol} / \mathrm{l}$ isotonic sodium chloride via the distal cannula, which was then clamped. Cholera toxin saline was evenly distributed throughout the small intestine and the abdomen closed. To establish the optimal dose of toxin and the exposure time required to produce maximal secretion, preliminary experiments were performed.

Time course of secretory response

In accordance with published reports ${ }^{16}$ a dose of $75 \mu \mathrm{g}$ of cholera toxin was initially instilled into the small intestine $(n=6)$ and a continuous isotonic $150 \mathrm{mmol} / \mathrm{l}$ sodium chloride perfusion was performed for 3.5 hours to assess the time of onset of secretion and the duration of the maximal secretory response. After a 30 minute equilibration period, sequential 10 minute collections for 3.5 hours were made and analysed for $\left[{ }^{14} \mathrm{C}\right]$-polyethylene glycol and sodium concentration. The onset of water secretion was rapid and was significant at 1 hour compared with perfusion of the same solution in normal small intestine $(p<0.01)$. It continued to increase up to 2 hours after exposure $(\mathrm{p}<0.05$; Fig 1A), but thereafter remained stable for the following 90 minutes. The pattern of sodium secretion followed that of water (data not shown). Subsequent experiments were therefore performed using a 2 hour exposure time. Mean (SD) weight loss of rats was $7 \cdot 8(1 \cdot 1) \%(n=6)$ during this experiment. This degree of weight loss would be regarded as equivalent to moderate dehydration in childhood gastroenteritis. ${ }^{17}$

\section{Optimal dose of cholera toxin}

ethylene glycol concentrations. The mean values of the three collections were used to calculate results. Only one solution was tested in each rat. At the end of the experiment rats were killed by exsanguination and the perfused segment of small intestine removed, dried in an oven at $90^{\circ} \mathrm{C}$ for 18 hours, and weighed. Each solution was tested in between six and 12 animals.

\section{ANALYTICAL METHODS}

Each 10 minute collection was analysed separately. Bicarbonate was measured immediately as total $\mathrm{CO}_{2}$ using a Corning 965 carbon dioxide analyser. Glucose content was estimated by the glucose oxidase method using a Technicon Autoanalyser. Sodium and potassium were determined by flame emission spectroscopy (Instrumentation Laboratory 943), osmolality by vapor pressure on a 5500 Vapor pressure osmometer (Wescor), and chloride by coulombmetric titration using a Chemlab CCMI chloride meter. $\left[{ }^{14} \mathrm{C}\right]$-polyethylene glycol was measured by liquid scintillation spectroscopy using an LKB 1210 Ultrabeta counter. Citrate content was determined using a commercial enzymatic method (Boehringer, Product No 139076).
A dose-response curve was constructed by assessing water (Fig 1B) and sodium secretion when $150 \mathrm{mmol} / \mathrm{l}$ isotonic sodium chloride was perfused in the normal small intestine and after a 2 hour exposure to increasing doses of cholera toxin $(5-100 \mu \mathrm{g})$. Significant secretion of sodium ( $p<0.01$; data not shown) but not of water occurred after a 2 hour exposure to a dose of $5 \mu \mathrm{g}$ toxin. Both water and sodium secretion $(\mathrm{p}<0.01)$ resulted with a dose of $50 \mu \mathrm{g}$ toxin, after which there was no significant increase in water (Fig 1B) or sodium secretion. As secretion was maximal and similar with doses ranging from $50-100 \mu \mathrm{g}$ toxin, we chose to use $75 \mu \mathrm{g}$ in subsequent experiments with oral rehydration solutions. Comparisons between different solutions were always made during the same period after a 2 hour exposure to toxin, during which time secretion was maximal and sustained.

Sections of jejunum and ileum taken after (i) exposure to toxin and (ii) exposure to toxin plus perfusion with the original World Health Organisation oral rehydration solution (WHOORS) were stained with haematoxylin and eosin and periodic acid-Schiff. No morphological changes were detected as expected, except for increased mucus secretion from goblet cells after exposure to cholera toxin. 
TABLE I Composition of oral rehydration solutions(ORS) ( $\mathrm{mmol} / \mathrm{l})$

\begin{tabular}{lccccc}
\hline & & ORSt & ORS‡ & ORSS & \\
& BNF-ORS & $60 / 111 C$ & $60 / 111 B$ & $60 / 140$ & WHO-ORS $\|$ \\
\hline Sodium & 35 & 60 & 60 & 60 & 90 \\
Chloride & 37 & 63 & 55 & 50 & 80 \\
Potassium & 20 & 25 & 25 & 20 & 20 \\
Glucose & 200 & 111 & 111 & 140 & 111 \\
Bicarbonate & 18 & - & 30 & 30 & 30 \\
Citrate & - & 10 & - & - & - \\
Osmolality (mOsmol/kg) & 310 & 289 & 281 & 300 & 331 \\
Glucose:sodium & 5.8 & 1.9 & 1.9 & 2.3 & 1.2 \\
\hline
\end{tabular}

^British National Formulary, sodium chloride and glucose powder compound.

†Nutricia ORS, containing citrate (C).

$¥$ Modification of Nutricia ORS, containing bicarbonate (B).

SExperimental ORS.

WWorld Health Organisation - ORS with bicarbonate.

TEST SOLUTIONS

A variety of established and experimental oral rehydration solutions were studied and their compositions are shown in Table I. Test solutions varied with respect to sodium (35-90 $\mathrm{mmol} / \mathrm{l})$ and glucose (111-200 $\mathrm{mmol} / \mathrm{l})$ concentrations, osmolality (281-331 $\mathrm{mOsmol} / \mathrm{kg}$ ), and ratio of glucose:sodium concentration $(1 \cdot 2-5 \cdot 8)$. Solutions contained either bicarbonate (18 or 30 $\mathrm{mmol} / \mathrm{l})$ or citrate $(10 \mathrm{mmol} / \mathrm{l})$. We compared the WHO-ORS, which is used extensively in developing communities, with the oral rehydration solutions used most commonly in the United Kingdom and recommended in the British National Formulary (BNF-ORS). ${ }^{18}$ This has a lower sodium concentration $(35 \mathrm{mmol} / \mathrm{l})$ and a higher glucose concentration $(200 \mathrm{mmol} / \mathrm{l})$ than the WHO-ORS. Recent clinical trials suggest that solutions containing a sodium concentration $\sim 60 \mathrm{mmol} / \mathrm{l}$ are equally effective for rehydration ${ }^{6}$ and avoid hypernatraemia, an occasional complication if the WHO-ORS is used incorrectly, especially in neonates. ${ }^{6} \mathrm{We}$ therefore studied this latter solution, ORS $60 / 111$ with both bicarbonate (ORS 60/111B) and citrate (ORS 60/111C), the latter being currently recommended by the WHO as an alternative base. Finally, we examined the effect of increasing the glucose concentration of this solution to $140 \mathrm{mmol} / \mathrm{l}$ to

(A)

Normal rat small intestine

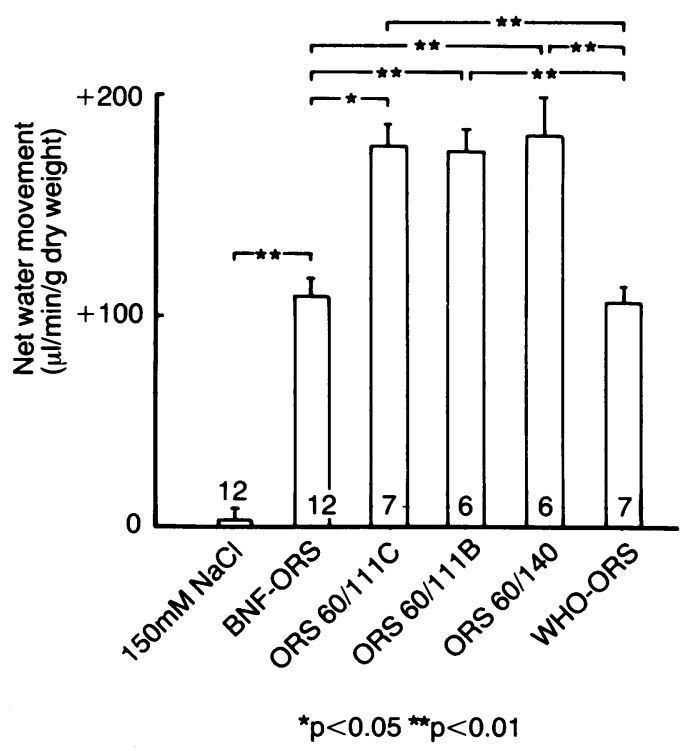

produce an experimental solution (ORS 60/140). The $150 \mathrm{mmol} / \mathrm{l}$ sodium chloride solution used as a control was rendered isotonic to rat plasma by the addition of $25 \mathrm{mmol} / 1 \mathrm{mannitol}$. Polyethylene glycol (PEG; mean molecular weight 4000 ) was added to all solutions as a nonabsorbable marker $\left(5 \mu \mathrm{Ci} / 1\left[{ }^{14} \mathrm{C}\right]-\mathrm{PEG}\right.$ with $2 \cdot 5$ $\mathrm{g} / \mathrm{l}$ unlabelled PEG), which enabled calculation of the rates of net water and solute movement. ${ }^{19}$ Mean (SEM) total PEG recovery in these experiments was $98(5) \%(n=100)$.

\section{CALCULATIONS}

Net absorption rates of water $(\mu \mathrm{l} / \mathrm{min} / \mathrm{g}$ dry weight of small intestine) and solutes ( $\mu \mathrm{mol} /$ $\mathrm{min} / \mathrm{g}$ dry weight of small intestine) were calculated from the measured concentrations of PEG and solute in the perfusates and the mean of the three 10 minute collections from the distal cannula. ${ }^{20}$ Net absorption (+) indicates a net transfer of water or solute from the lumen; net secretion (-) indicates net transfer of water or solute into the lumen. Results are expressed as mean (SEM).

\section{STATISTICAL METHODS}

Differences in water and solute movement with different solutions were examined statistically using analysis of variance, and differences between pairs of individual means were tested using the Scheffe test (SAS statistical package).

\section{Results}

All results are expressed as mean (SEM) unless otherwise specified.

PERFUSION WITH ISOTONIC SODIUM CHLORIDE

As expected, minimal net water $(+1.59(7.05)$ $\mu \mathrm{l} / \mathrm{min} / \mathrm{g})(\mathrm{Fig} \mathrm{2A})$ and sodium $(+5 \cdot 18(1.03)$

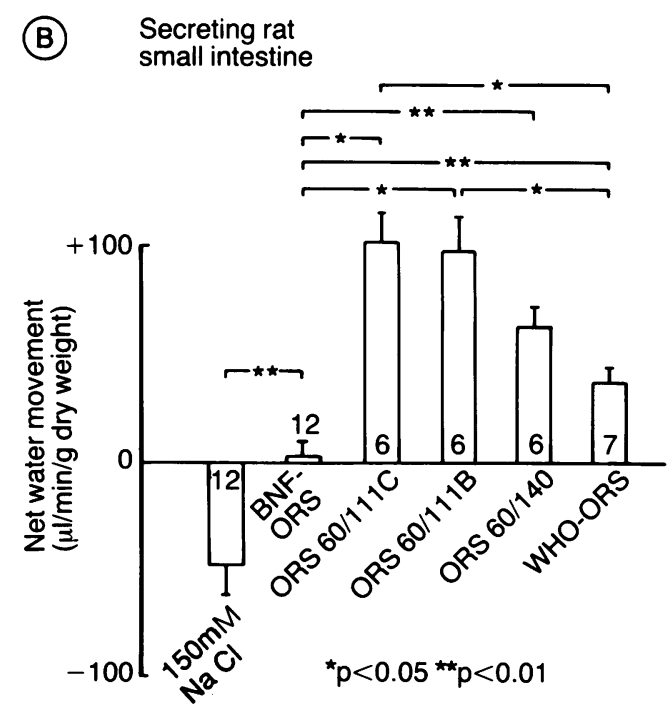

Figure 2: (A) Water absorption from oral rehydration solutions $(O R S)$ in normal rat small intestine. $+=$ net water absorption, shown as mean (SEM). The number of animals in each group is shown. (B) Water absorption from solutions in secreting rat small intestine. $+=$ net water absorption; $-=$ net secretion, shown as mean (SEM). The number of animals in each group is shown. 
TABLE II Net solute movement during 150 mmoll isotonic saline perfusion in normal and secreting small intestine ${ }^{\star}$

\begin{tabular}{lll}
\hline $\begin{array}{l}\text { Net small } \\
\text { intestinal transport }\end{array}$ & $\begin{array}{l}\text { Normal intestine } \\
(n=12)\end{array}$ & $\begin{array}{l}\text { Secreting intestine } \\
(n=12)\end{array}$ \\
\hline Sodium & $+5 \cdot 18(1 \cdot 03)$ & $-3 \cdot 37(2 \cdot 09) \dagger$ \\
Chloride & $+7 \cdot 22(1 \cdot 4)$ & $+1 \cdot 42(1 \cdot 7) \ddagger$ \\
Potassium & $-1 \cdot 31(0 \cdot 1)$ & $-1 \cdot 6(0 \cdot 1)$ \\
Bicarbonate & $-2 \cdot 34(0 \cdot 13)$ & $-4 \cdot 68(0 \cdot 59) \dagger$ \\
\hline
\end{tabular}

*Net transport of solute is expressed as $\mu \mathrm{mol} / \mathrm{min} / \mathrm{g}$ dry weight of small intestine.

$+=$ absorption; $-=$ secretion

Results are mean (SEM). The level of significance of the difference between movement in the normal and the secreting intestine is shown by: $t p<0.01 ; \ddagger p<0.001$.

$\mu \mathrm{mol} / \mathrm{min} / \mathrm{g}$ ) (Table II) absorption occurred on perfusion of the normal small intestine with isotonic $150 \mathrm{mmol} / \mathrm{l}$ sodium chloride. Compared with perfusion in the normal intestine, significant water $(-47.8(11.8) \mu \mathrm{l} / \mathrm{min} / \mathrm{g} ; \mathrm{p}<0.01)(\mathrm{Fig}$ 2B) and sodium $(-3.37(2.09) \mu \mathrm{mol} / \mathrm{min} / \mathrm{g}$; $\mathrm{p}<0.01$ ) (Table II) secretion was reliably and reproducibly produced when the intestine was treated with cholera toxin before perfusion with this solution. In the secreting intestine significantly less chloride absorption and more bicarbonate secretion also occurred than in the normal intestine (Table II).

RELATIVE EFFICACY OF SOLUTIONS IN PROMOTING WATER ABSORPTION

All five solutions tested promoted net water absorption in the normal small intestine (Fig 2A) and reversed net secretion to absorption in the secreting intestine (Fig 2B), though to varying degrees. Although the pattern of water absorption was similar, the amount of water absorbed from each solution was significantly less in the secreting intestine than from the same solution in the normal intestine $(\mathrm{p}<0.01$ for all solutions). In normal intestine the efficacy of the $35 \mathrm{mmol} / \mathrm{l}$ sodium BNF-ORS and the $90 \mathrm{mmol} / \mathrm{l}$ sodium WHO-ORS was similar. In secreting intestine, however, the WHO-ORS promoted more water absorption than the BNF-ORS $(p<0.01)$. In both normal and secreting intestine the two solutions containing $60 \mathrm{mmol} / \mathrm{l}$ sodium and 111 $\mathrm{mmol} / \mathrm{l}$ glucose (ORS 60/111C, ORS 60/111B) were equally effective. Both were superior to the low sodium (BNF-ORS) and high sodium (WHO-ORS) solutions in promoting water absorption (in normal and secreting intestines). The ORS 60/140 was as effective as these two solutions and superior to the BNF-ORS $(\mathrm{p}<0.01)$ in both normal and secreting intestine. In normal intestine it was also superior to the WHO-ORS $(\mathrm{p}<0.01)$; however, in the secreting intestine it resulted in similar water absorption to the WHO-ORS.

EFFECT OF CHOLERA TOXIN ON GLUCOSE AND ELECTROLYTE MOVEMENT FROM SOLUTIONS

Net movement of sodium (Fig 3A and B) and electrolytes (Table III) from the five solutions are shown in normal and secreting intestine. Net sodium and chloride secretion occurred with all solutions in the secreting intestine. This was significantly different from the movement of these electrolytes in the normal intestine $(\mathrm{p}<0.01$ for all solutions) in which absorption occurred from all but the BNF-ORS. With this low sodium solution net sodium and chloride secretion occurred in normal as well as secreting intestine, despite net water absorption.

Glucose absorption from the high glucose BNF-ORS was significantly higher in the normal than secreting intestine $(\mathrm{p}<0 \cdot 01)$. With all other solutions there was no difference in glucose absorption between normal and secreting intestine. Potassium absorption from BNFORS, WHO-ORS, and ORS 60/140 was greater in normal than secreting intestine $(\mathrm{p}<0.001)$.

Bicarbonate absorption occurred from all solutions containing bicarbonate in the normal intestine and secretion from the solution containing citrate. In the secreting intestine bicarbonate absorption was significantly less than from the same solutions in the normal intestine $(\mathrm{p}<0.01)$. In the case of ORS $60 / 111 \mathrm{C}$ increased bicarbonate secretion occurred $(\mathrm{p}<0 \cdot 01)$. Citrate absorption from ORS 60/111C occurred in normal and secreting intestines to a similar extent.

\section{(A) Normal rat \\ small intestine}
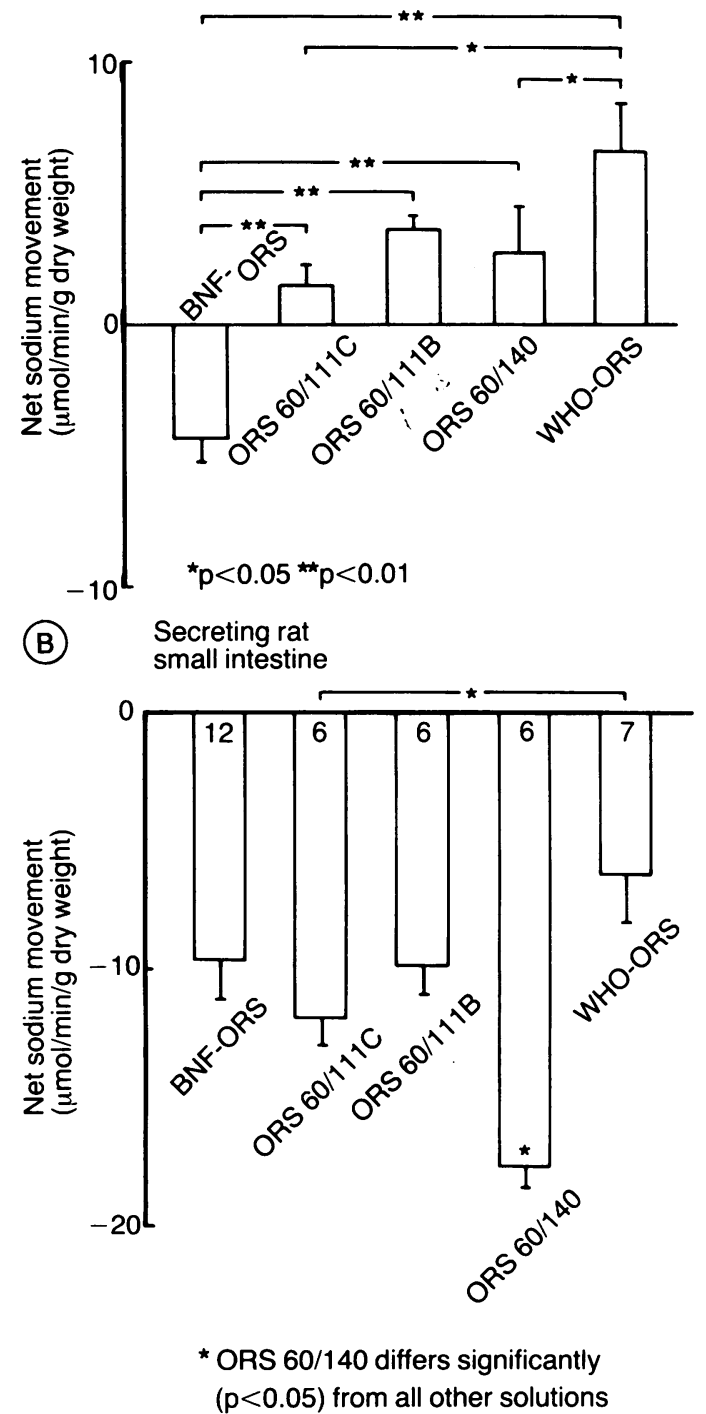

Figure 3: (A) Sodium movement from oral rehydration solutions $(O R S)$ in normal rat small intestine. Results are shown as mean (SEM). The number of animals in each group is shown. (B) Sodium movement from solutions in secreting rat small intestine. Results are shown as mean (SEM). The number of animals in each group is shown. 
TABLE III Net solute movement ( $\mathrm{mmol} / \mathrm{l})$ from oral rehydration solutions in normal and secreting rat small intestine ${ }^{\star}$

\begin{tabular}{|c|c|c|c|c|c|c|}
\hline Solution & No & Chloride & Glucose & Potassium & Bicarbonate & Citrate \\
\hline \multicolumn{7}{|l|}{ Normal intestine: } \\
\hline BNF-ORS & 12 & $-4 \cdot 63(\cdot 9) \ddagger$ & $+40.9(3.4) \|$ & $+7.03(0.25) \|$ & $+5.77(0.41)$ & - \\
\hline ORS 60/111C & 7 & $+5.41(0.36) \dagger$ & $+28.5(1.73)$ & $+5.63(0.24)$ & $-2.91(0.86)+\|$ & $+3 \cdot 0(0 \cdot 18)$ \\
\hline ORS 60/111B & 6 & $+4.69(0.97) \dagger$ & $+27 \cdot 04(3 \cdot 0)$ & $+6.74(0.89)$ & $+6.77(0.56) \|$ & - \\
\hline ORS $60 / 140$ & 6 & $+3 \cdot 72(0.86) \dagger$ & $+35 \cdot 0(4 \cdot 29)$ & $+6.47(0.95) \|$ & - & - \\
\hline WHO-ORS & 7 & $+3.89(0.82) \dagger$ & $+28 \cdot 56(3 \cdot 16)$ & $+4.59(0.36)$ & $+5.67(0.77) \|$ & - \\
\hline \multicolumn{7}{|c|}{ Secreting intestine: } \\
\hline BNF-ORS & 12 & $-6 \cdot 04(1 \cdot 25)$ & $+18 \cdot 72(2 \cdot 13)$ & $+4 \cdot 20(0 \cdot 56)$ & $+0.46(0.52)$ & - \\
\hline ORS 60/111C & 6 & $-4 \cdot 13(0.87)$ & $+32.91(1.88)$ & $+5 \cdot 1(0.5)$ & $-7.46(0.6)$ & $+3 \cdot 27(0 \cdot 19)$ \\
\hline ORS 60/111B & 6 & $-3 \cdot 87(0 \cdot 88)$ & $+33 \cdot 13(3 \cdot 22)$ & $+5.91(0.52)$ & $+1.36(0.64)$ & - \\
\hline ORS 60/140 & 6 & $-8.25(0.73)$ & $+33 \cdot 7(2 \cdot 36)$ & $+3 \cdot 40(0 \cdot 15)$ & $-2 \cdot 62(0 \cdot 28)$ & - \\
\hline WHO-ORS & 7 & $-3 \cdot 52(1 \cdot 18)$ & $+28 \cdot 6(1.5)$ & $+2 \cdot 73(0 \cdot 13)$ & $-0.26(0.57)$ & - \\
\hline
\end{tabular}

^Net movement of solute is expressed as $\mu \mathrm{mol} / \mathrm{min} / \mathrm{g}$ dry weight of small intestine; $+=$ absorption; $-=$ secretion. Results are mean $(S E M) .+p<0.01$ compared with movement from the same ORS in secreting intestine; $\neq \mathrm{p}<0.05$ compared with other ORSs in normal intestine; $\delta \mathrm{p}<0.05$ compared with other ORSs in secreting intestine; $\| p<0.001$ compared with movement from the same ORS in secreting intestine.

\section{RELATION BETWEEN THE SODIUM}

CONCENTRATION OF SOLUTIONS AND SODIUM MOVEMENT

Net sodium movement from the solutions is shown in normal (Fig 3A) and secreting (Fig 3B) intestine. A relation between the sodium content of solutions and sodium movement is most obvious in the normal intestine. To further evaluate the relation between sodium content and sodium movement, the five solutions were also considered with base (citrate or bicarbonate) and after its exclusion. Individual values of sodium movement in normal $(n=68)$ and secreting $(n=68)$ intestine were plotted against sodium concentration $(35,60$, or $90 \mathrm{mmol} / \mathrm{l})$ as shown in Figure 4. Mean values for sodium movement for
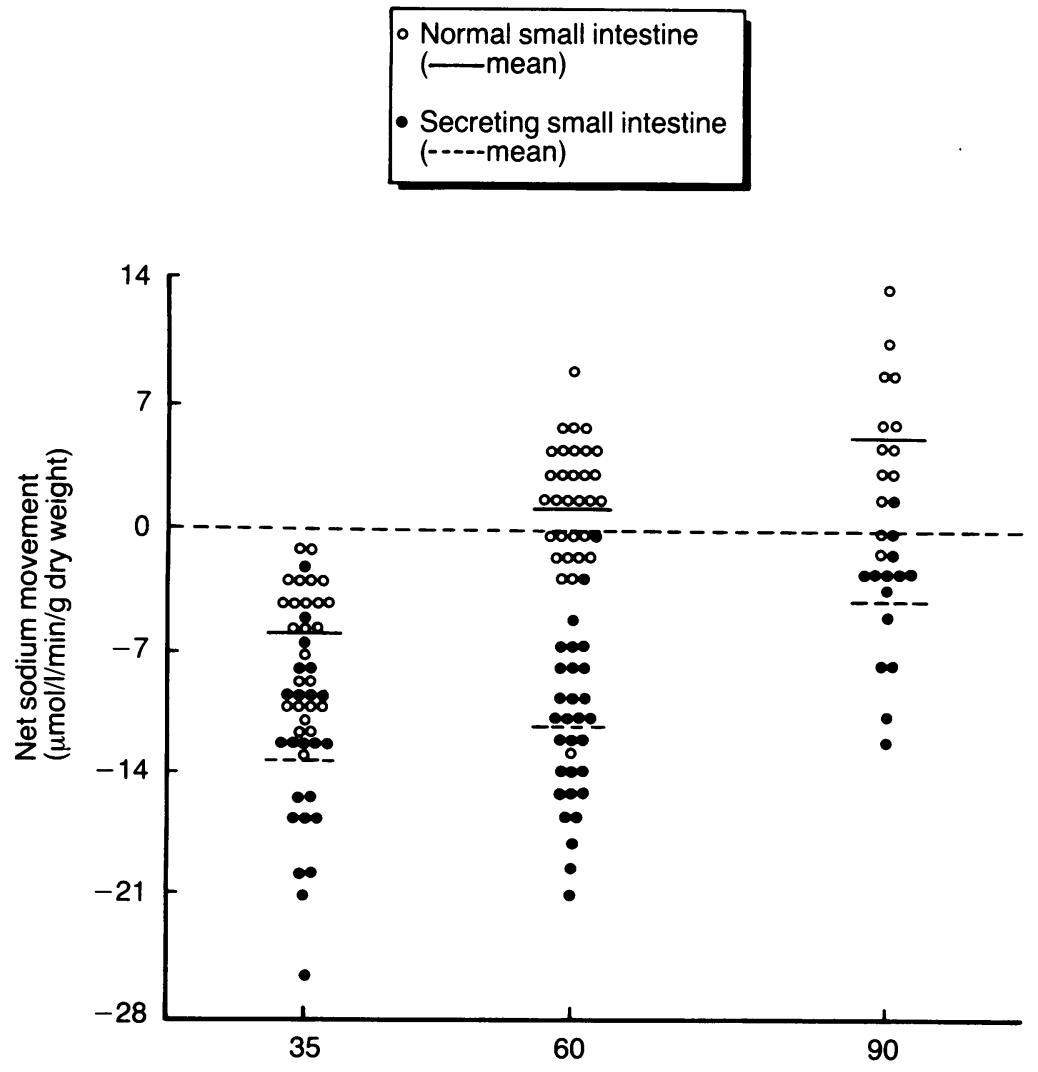

ORS sodium concentration ( $\mathrm{mmol} / \mathrm{l})$

Figure 4: Relation between sodium concentration in the solutions (ORS) and net sodium movement in normal and secreting rat small intestine. Individual values of sodium movement from $O R S$ s with and without base are shown. each sodium concentration were also calculated and compared in normal and secreting intestine.

In the normal intestine there was a significant positive correlation between net sodium movement and the sodium concentration of the solutions $(r=0.74 ; p<0.01)$ (Fig 4). Mean (SEM) net sodium secretion $(-6.08(0.67) \mu \mathrm{mol} / \mathrm{min} / \mathrm{g})$ occurred when low sodium $(35 \mathrm{mmol} / \mathrm{l})$ solutions were perfused. Minimal mean net sodium absorption $(+1.41(0.68))$ occurred with solutions containing $60 \mathrm{mmol} / \mathrm{l}$ sodium and this was significantly higher than from low sodium solutions $(p<0.01)$. Significantly higher mean sodium absorption $(+4.98(1 \cdot 13))$ occurred with solutions containing $90 \mathrm{mmol} / \mathrm{l}$ sodium than with those containing $60 \mathrm{mmol} / \mathrm{l}$ sodium $(\mathrm{p}<0.01)$. Thus in the normal intestine mean net sodium absorption occurred only when the sodium concentration was $\geqslant 60 \mathrm{mmol} / \mathrm{l}$. In contrast, net sodium secretion occurred with all solutions tested in the secreting intestine. The amount of sodium secretion was related to the sodium concentration $(r=0.52, p<0.01)$, being greatest with solutions containing $35 \mathrm{mmol} / \mathrm{l}$ sodium $(-12.75(1.11) \mu \mathrm{mol} / \mathrm{min} / \mathrm{g})$ and decreasing with sodium concentrations of $60(-11.31(0.94)$ and $90 \mathrm{mmol} / \mathrm{l}(-4.55(1.11) ; \mathrm{p}<0.01)$. By extrapolation net sodium absorption in this model would be expected only when the sodium concentration was $\geqslant 120 \mathrm{mmol} / \mathrm{l}$. Net water and glucose absorption occurred with all solutions despite the net sodium secretion observed with low sodium in normal intestine and with all solutions in the secreting intestine.

\section{RELATION BETWEEN THE GLUCOSE CONCENTRATION OF SOLUTIONS AND GLUCOSE MOVEMENT}

Glucose absorption in normal intestine was similar from all solutions with glucose concentrations from 111 to $200 \mathrm{mmol} / \mathrm{l}$ (Table III). In secreting intestine glucose absorption was significantly less from the BNF-ORS than from all other solutions $(p<0.05)$. Thus, if glucose absorption from the solution with a high glucose concentration is similar to or less than that from solutions with low glucose, a larger amount remains unabsorbed in the lumen and probably exerts an osmotic effect which could account for the low water absorption from the high glucose solution in both normal and secreting intestine.

EFFECT OF GLUCOSE:SODIUM CONCENTRATION RATIO IN SOLUTIONS ON WATER ABSORPTION In an attempt to relate these two variables the ratio between the glucose and sodium concentrations was calculated and its effect on water movement was analysed. Water absorption was significantly greater from solutions with a ratio of glucose:sodium concentration of approximately $2(1 \cdot 9-2 \cdot 3)$, than from those with a ratio of $1 \cdot 2$ $(\mathrm{p}<0.01)$ or $5.8(\mathrm{p}<0.01)$.

EFFECT OF OSMOLALITY ON WATER ABSORPTION There was a significant negative correlation between the osmolality of solutions and water absorption in normal $(\mathrm{r}=0.52 ; \mathrm{p}<0.01 ; \mathrm{n}=68)$ 
and secreting $(\mathrm{r}=0.51 ; \mathrm{p}<0.01 ; \mathrm{n}=68)$ intestine. Mean water absorption in normal intestine was less from each of the hypertonic solutions $(310$ and $331 \mathrm{mOsmol} / \mathrm{kg}$ ) than from those which were hypotonic $(281 \mathrm{mOsmol} / \mathrm{kg}, \mathrm{p}<0.01)$ and isotonic (289 and $300 \mathrm{mOsmol} / \mathrm{kg}, \mathrm{p}<0.01$ ). The pattern of water absorption in relation to osmolality was similar in normal and secreting intestine, although in secreting intestine there was no difference in water absorption from solutions with osmolalities of 300 and 331 $\mathrm{mOsmol} / \mathrm{kg}$.

\section{Discussion}

Although acute diarrhoeal disease, including cholera, remains a major threat to children world wide, mortality and morbidity have decreased dramatically with the introduction of oral rehydration treatment. ${ }^{12}$ However, the suitability of an oral rehydration solution for prevention and treatment of dehydration associated with diarrhoea varies with the aetiology. In viral gastroenteritis, which predominates in developed communities, for example, water loss is relatively greater than stool sodium loss, which is more important in secretory diarrhoeas including cholera. The WHO recommends a single solution for use in developing communities Many alternative solutions have been formulated in developed communities but due to the difficulties in conducting clinical trials many are marketed before being adequately evaluated. Although previous workers have used intestinal perfusion of the normal rat intestine to access the efficacy of solutions, ${ }^{10-13}$ few have attempted such studies in disease states ${ }^{14}$ or compared results obtained in normal and abnormal intestine. In our studies quantitative differences in water and solute movement in the normal and secreting intestines were observed, suggesting that results obtained in the normal intestine should be extrapolated to disease states with caution.

Reversal of net water secretion to absorption by all solutions confirms intact glucose-sodium co-transport in this model of experimental cholera, ${ }^{3}$ although the degree of water absorption varied considerably with the composition of the solution. Maximum water absorption occurred from solutions which were hypotonic or isotonic with respect to rat plasma, thus the influence of the osmolality of the solution on water absorption, which has been shown previously in the normal rat intestine, ${ }^{13}$ is now confirmed in the secreting intestine.

Solutions containing $60 \mathrm{mmol} / \mathrm{l}$ sodium and 111-140 mmol/l glucose promoted more water absorption than those with a high sodium content or with a low sodium and high glucose content in both normal and secreting intestine. In these solutions the molar ratio of glucose: sodium was approximately two. The importance of this finding is unclear, although Lifshitz and Wapnir $^{1013}$ have obtained similar results in studies of normal rat jejunum. As this model measures net movement of water and electrolytes only, it does not enable study of the glucosesodium transport mechanism. The absolute concentrations of sodium and glucose in oral rehydration solutions may be more relevant than the ratio. Solutions with a similar composition have also been successfully used clinically in Europe $^{2122}$ and the United States, ${ }^{5}$ and compare favourably with the WHO-ORS for efficacy and safety in the treatment of dehydration, electrolyte disturbance, and acidosis associated with acute gastroenteritis. ${ }^{6}$ The poor water absorption observed with the BNF-ORS may relate to its high glucose concentration, which seems to exceed that required for optimal water absorption. ${ }^{23}$ With this solution a relatively larger proportion of glucose must remain unabsorbed in the lumen where it is available to exert an osmotic pressure and perpetuate water loss resulting in the low water absorption found. The clinical observation that children receiving a high glucose solution are more likely to have carbohydrate intolerance and more frequent watery stools supports this conclusion. ${ }^{22}$ The low sodium content of this solution, which results in pronounced sodium secretion, probably also contributes to poor water absorption. In view of both clinical $^{62}$ and experimental evidence for the inferiority of low sodium, high glucose solutions, consideration should be made by the British National Formulary to stop recommending its use in the UK. The WHO-ORS also performed poorly in both normal and secreting intestine in this model and is considered by clinicians to be unsuitable for widespread use in developed communities where diarrhoea is predominantly viral in aetiology and stool sodium losses are relatively low. ${ }^{6}$ It therefore seems logical to recommend a mid-sodium solution which promotes more water absorption experimentally and has been proved effective and safe clinically. ${ }^{562122}$

Net sodium movement was directly related to the sodium concentration of the solution and supports similar observations made in normal human jejunal perfusion studies. ${ }^{24}$ Interestingly, net water absorption occurred independently of net sodium absorption from some solutions. In the normal rat intestine only solutions containing $\geqslant 60 \mathrm{mmol} / \mathrm{l}$ sodium resulted in net sodium absorption, although all resulted in net water absorption. In the secreting intestine all solutions resulted in net sodium secretion, although all resulted in net water absorption. Net sodium absorption in the secreting intestine would, by extrapolation, only occur at sodium concentrations of $\geqslant 120 \mathrm{mmol} / \mathrm{l}$ in this model. Obviously a solution with such a high sodium concentration would not be considered safe in children. In view of our findings hypernatraemia seems an unlikely complication of treatment with currently available solutions unless they are incorrectly reconstituted. ${ }^{25}$ Hypernatraemia may occur when high sodium solutions are used in neonates ${ }^{26}$ or if given without additional free water for maintenance treatment. ${ }^{30}$ Conversely the use of low sodium solutions, particularly in secretory diarrhoeas, may also predispose to clinical hyponatraemia, as has been shown in the rat $^{14}$ and in clinical trials using low sodium solutions for non-secretory diarrhoea. ${ }^{92}$ It is of interest that in the early studies in adults with cholera $^{29}$ net positive sodium balance was not achieved despite successful rehydration with intragastric solutions containing 101-118 
$\mathrm{mmol} / \mathrm{l}$ sodium. Stool sodium losses were, however, significantly decreased in patients receiving glucose-saline solutions compared with those receiving only saline. The role of the colon in salvaging sodium and water may be considerable, and the exclusion of the colon is an obvious limitation of this model. However, one recent study has confirmed that colonic absorptive function is defective in cholera. ${ }^{30}$ We hope to extend these studies to evaluate the effect of the colon on absorption of oral rehydration solutions.

Net glucose absorption was similar in normal intestine whether the solution contained 111 , 140 , or $200 \mathrm{mmol} / \mathrm{l}$ glucose. Glucose absorption, however, was lower from solutions containing $200 \mathrm{mmol} / \mathrm{l}$ glucose in the secreting intestine. Although the explanation for this is unclear, it seems that the secreting intestine is less able to deal with a high glucose content solution than the normal intestine. Water absorption was also lower with this solution in both normal and secreting intestines, suggesting that unabsorbed luminal glucose was decreasing water absorption by an osmotic effect. The high glucose solution had a glucose:sodium ratio of approximately 6 . The optimum ratio of glucose:sodium concentration for promotion of water absorption was approximately 2 in both normal and secreting intestine in this model.

The development of this model of secretory diarrhoea and its use in conjunction with in situ small intestinal perfusion has enabled the assessment of solutions in a disease-like state. It highlights the danger of applying results obtained in normal intestine to pathological states. The model seems to be capable of differentiating between solutions of different efficacy; however, extrapolation to clinical practice must be made with care due to the limitations of the model, in particular the exclusion of the colon. Although a direct parallel between the secretory model and human diarrhoeal states has not been established, recent work shows a parallel between results obtained in the normal rat and human intestinal models, ${ }^{3132}$ suggesting these animal studies will be a useful guide to further clinical research into oral rehydration solutions for use in acute gastroenteritis. The recent development of a model of human cholera $\mathrm{a}^{33}$ and its application to evaluating solutions should provide further useful information.

MJGF is a Wellcome Trust Senior Lecturer and is grateful to the Wellcome Trust for financial assistance. We thank Nutricia, Cow \& Gate Ltd for financial support, Dr John Beckett for statistical advice, and Ms Nicola Herrera for typing the manuscript.

1 Anonymous. Water with sugar and salt [Editorial]. Lance 1978; ii: 300-1.

2 Pierce NF, Hirschhorn N. Oral fluid - a simple weapon agains dehydration in diarrhoea. WHO Chron 1977; 31: 87-93.

3 Pierce NF, Sack RB, Mitra RC, et al. Replacement of wate and electrolyte losses in cholera by an oral glucose electrolyt solution. Ann Intern Med 1969; 70: 1173-81.

4 Hirschhorn $\mathrm{N}$. The treatment of acute diarrhea in children. An historical and physiological perspective. Am $\mathcal{f}$ Clin Nutr 1980; 33: 637-63.
5 Santosham M, Daum RS, Dillman L, et al. Oral rehydration therapy of infantile diarrhea. A controlled study of wellnourished children hospitalized in the United States and Panama. N Engl F Med 1982; 306: 1070-6.

6 Elliott EJ, Cunha-Ferreira RCM, Walker-Smith JA, Farthing MJG. Sodium content of oral rehydration solutions: a reappraisal. Gut 1989; 30: 1610-21.

7 Elliott EJ, Walker-Smith JA, Farthing MJG. The role of bicarbonate and base precursors in the treatment of acute gastroenteritis. Arch Dis Child 1987; 62: 91-5.

8 Islam MR, Ahmed SM. Oral rehydration solution without bicarbonate. Arch Dis Child 1984; 59: 1072-5.

9 Elliott EJ, Armitstead JCM, Farthing MJG, Walker-Smith JA. Oral rehydration therapy without bicarbonate for prevention and treatment of dehydration: a double-blind controlled trial. Aliment Pharmacol Therap 1988; 2: 253-62.

10 Lifshitz F, Wapnir RA. Oral hydration solutions: experimental optimization of water and sodium absorption f Pediatr 1985; 106: 383-9.

11 Patra FC, Mahalanabis D, Jalan KN. Stimulation of sodium and water absorption by sucrose in the rat small intestine. Acta Paediatr Scand 1982; 71: 103-7.

12 Saunders DR, Sillery JK. Absorption of carbohydrateelectrolyte solutions in rat duodenojejunum. Implications for the composition of oral electrolyte solutions in man. Dig Dis Sci 1985; 30: 154-60.

13 Wapnir RA, Lifshitz F. Osmolality and solute concentrationtheir relationship with oral hydration solution effectiveness: on experimental assessment. Pediatr Res 1985; 19: 894-8.

14 Rolston DDK, Borodo MM, Kelly MJ, Dawson AM, Farthing MJG. Efficacy of oral rehydration solutions in a rat model of secretory diarrhea. $\mathcal{F}$ Pediatr Gastroenterol Nut 1987; 6: 624-30.

15 Elliott EJ, Watson AJM, Walker-Smith JA, Farthing MJG Effect of bicarbonate on efficacy of oral rehydration therapy: studies in an experimental model of secretory diarrhoea. Gut 1988; 29: 1052-7.

16 Donowitz M, Charney AN, Hynes R. Propranolol prevention of cholera enterotoxin-induced intestinal secretion in the rat. of cholera enterotoxin-induced in

17 Walker-Smith JA, Hamilton JR, Walker WA, eds. Practical paediatric gastroenterology. London: Butterworth, 1983: 66.

18 British national formulary. London: British Medical Associa tion and the Pharmaceutical Society of Great Britain, 1986 11: 290

19 Borgstrom B, Dahlquist A, Lundh G, Sjovall J. Studies of intestinal digestion and absorption in the human. $7 \mathrm{Clin}$ Invest 1957; 36: 1521-36.

20 Sladen GE, Dawson AM. An evaluation of perfusion techniques in the study of water and electrolyte absorption in man: the problem of endogenous secretions. Gut 1968; 9: 530-5.

21 Isolauri $\mathrm{E}$. Evaluation of an oral rehydration solution with $\mathrm{Na}^{+}$ $60 \mathrm{mmol} / \mathrm{l}$ in infants hospitalized for acute diarrhoea or

22 Elliott EJ, Da Cunha-Ferreira RMC, Cameron D, Farthin MJG, Walker-Smith JA. Evaluation of three oral rehydration solutions designed for use in developed countries. Aliment Pharmacol Therap 1989; 3: 233-43.

23 Sladen GE, Dawson AM. Interrelationships between the absorptions of glucose, sodium and water by the normal human jejunum. Clin Sci 1969; 36: 119-32.

24 Spiller RC, Jones BJM, Silk DBA. Jejunal water and electrolyte absorption from two proprietary enteral feeds in man importance of sodium content. Gut 1987; 28: 681-7.

25 Hutchins P, Wilson C, Manly JAE, Walker-Smith JA. Ora solutions for infantile gastroenteritis - variations in composisolutions for infantile gastroenteritis
tion. Arch Dis Child 1980; 55: 616-8.

26 Bhargava SK, Sachdev HPS, Das Gupta B, et al. Oral therap of neonates and young infants with dehydrating diarrhea: comparison of low and standard sodium content in ora rehydration solutions. $\mathcal{F}$ Pediatr Gastroenterol Nutr 1984; 3 . $500-5$.

27 World Health Organisation/UNICEF. Oral rehydration salts. Planning, establishment and operation of production facilities. Geneva: WHO 1985: 85: 1-136.

28 Cutting WAM, Belton NR, Gray JA, et al. The safety and efficacy of three oral rehydration solutions for children with diarrhoea. Acta Paediatr Scand 1989; 78: 253-8.

29 Hirschhorn N, Kinzie JL, Sachar DB, et al. Decrease in ne stool output in cholera during intestinal perfusion with glucose-containing solutions. $N$ Engl $\mathcal{J}$ Med 1968; 279. glucose-coi

30 Speelman P, Butler T, Kabir I, Ali A, Banwell J. Colonic dysfunction during cholera infection. Gastroenterology 1986 91: $1164-70$

31 Hunt JB, Elliott EJ, Farthing MJG. Comparison of rat and human intestinal perfusion models for assessing efficacy of oral rehydration solutions. Aliment Pharmacol Therap 1991; 5: 49-59.

32 Hunt JB, Salim AFM, Thillainyagam AV, Carnaby S, Elliot $\mathrm{E}$, Clark ML, et al. Evaluation of a hypotonic oral rehydration solution (ORS) in mammalian models. Gut 1988; 29. A1470.

33 Hunt JB, Carnaby S, Farthing MJG. Use of a model of huma cholera to study hypotonic oral rehydration solutions. Gut 1989; 30: A 1510 . 